\title{
Ülke Örnekleri ile Evde Bakım Hizmetlerine Genel Bakış
}

\author{
Overviiew of Home Care Services with Country Examples
}

\author{
Asu GÜRER
}

ÖZ

Evde Bakım Hizmetlerinin tanımı, 25751 sayılı Resmi Gazete'de "Evde Bakım Hizmetleri'nin Sunumu Yönetmeliği" çerçevesinde; sağl1k hizmetlerinin hekim önerisi doğrultusunda, profesyonel bir ekip tarafından hastalara, kişinin kendi evinde ya da yaşadığ 1 ortamda, rehabilite edici hizmetler, fizik tedavi hizmetleri, psikolojik destek tedavisi de dâhil olmak üzere tıbbi ihtiyaçların karşılanacak şekilde sunulması" şeklinde yapılır. Evde bakım hizmetleri ile alternatif bir sağlık hizmeti sunulduğundan bu hizmetlerinin sağlık hizmetleri içindeki yeri önemlidir. $\mathrm{Bu}$ derlemenin amacı literatür bilgisinden faydalanarak evde bakım hizmeti ve Türkiye'de bu hizmetlerin sunumu hakkında bilgi sunmaktır. Türkiye'de sunulan hizmetin kalite ve verimliliğini artırmak, eleştirel bir bakış kazanmak için gelişmiş ülkelerden örnek uygulamalara yer verilmiş ve öneriler sunulmuştur.

Anahtar Kelimeler: Evde bakım, sağlık hizmeti, sağlık profesyoneli, Türkiye.

\begin{abstract}
Definition of Home Care Services, in the Official newspaper No. 25751, within the framework of "Regulation on Presentation of Home Care Services"; health services are provided by a professional team in line with the physician's suggestion, to the patients, in the home or in the environment where they live, to meet the medical needs including rehabilitative services, physical therapy services, psychological support therapy". As an alternative health service is offered with home care services, the place of these services in health services is important. This literature review aims advantage of home care services in Turkey and to provide information about the provision of these services. To increase the quality and efficiency of services offered in Turkey, given
\end{abstract}

Asu GÜRER (四)

Marmara Üniversitesi Sağllk Hizmetleri Meslek Yüksekokulu, Anestezi Programı, D-100 Güney Yan Yolu Üzeri, Cevizli Mahallesi, 34865 Kartall, Istanbul

e-mail: asu.gurer@marmara.edu.tr the example of the developed countries to gain a critical view of applications and proposals were presented.

Keywords: Home care, health care, health professional, Turkey.

\section{GIRISS}

Evde bakım hizmetleri; özürlü, yaşlı, süre gelen rahatsızlığ 1 olan ya da hastalıktan sonra derlenme döneminde olan kişileri kendi evlerinde veya bulundukları ortamda onları destekleyip toplumla bütünleşmelerini sağlamayı amaçlayan, hem bireye hem de aileye sunulan psikolojik, fizyolojik, tıbbi ve sosyal destek hizmetlerini kapsayan bir hizmet modelidir (1). Sağlık, ekonomik ve sosyal hizmet gibi alanlarda bu işte uzman kişiler aracılı̆g ile sunulur (2). Evde Bakım Hizmetleri'nin Sunumu Yönetmeliği çerçevesinde; "sağlık hizmetlerinin hekim önerisi doğrultusunda, profesyonel bir ekip tarafından hastalara, kişinin kendi evinde ya da yaşadığı ortamda, rehabilite edici hizmetler, fizik tedavi, psikolojik destek tedavisi de dâhil kişinin tıbbi gereksinimlerini karşılayacak şekilde hizmet sunumu" şeklinde tanımlanır (3).

Eski çağlardan beri evde bakım sağlanmış olmasına rağmen sunulan hizmet modern tıp hizmetinden uzak olmuştur. Türkiye'de düzenleyici faaliyetlerden önce bakım verenler ve bakım alanlar çeşitli sorunlarla karşılaşmışlardır. (4). Bakımdan sorumlu bireylerde özgürlüklerinin kısıtlandığ sorunlarının ortaya çıktığı bildirilmiştir $(2,4)$. Aileler üzerinde yapılan araştırmalardan elde edilen verilere göre; aile bireylerinin \%66.2'sinin aile içindeki rollerinin değiştiğini, \%66'sı yorgunluk, iç sıkıntısı, sosyal hayatta değişiklikler yaşadığını, sorunlarını çözebilmek amacıyla da evlerinde sağlık çalışanı istediklerini belirtmişlerdir $(3,4)$. Başka bir çalışmaya göre, bakım verenlerin $\% 84$ 'ü 
evde hasta bakımı hakkında bilgilendirme almadıklarını, bakım sunanların \%74,2'si profesyonel yardıma ihtiyaç duyduklarını belirtmiş̧lerdir (5).

Bu çalışmada evde bakım hizmetinin önemi, hizmetin sunumu, avantaj ve dezavantajları ile genel bir bakış sağlanmış, Türkiye'de ve gelişmiş evde bakım hizmet modelleri olan Avrupa ülkelerindeki uygulamalardan bahsedilip öneriler sunulmuştur.

\section{EVDE BAKIM HIZMETLERİ}

1.1. Hizmetin Sınıflandırılması: Bireylerin ihtiyaçları doğrultusunda sosyal hizmetleri de içine alır. Tıbbi hizmetin öncelikli olduğu, hastalıktan sonraki 30 günlük iyileşme dönemi içinde sunulan kısa süreli hizmetler, tıbbi bakımın yanında sosyal bakım hizmetlerini de içine alan, altı aydan daha fazla bakıma ihtiyaç duyan bireylere ise uzun süreli hizmetler sunulmaktadır. Farklı meslek alanlarındaki uzmanlar formal bakım, akraba, aile üyeleri gibi kişiler informal bakım hizmeti sunarlar $(1,6)$.

1.2. Evde Bakım Hizmetlerinin Amacı: Bu hizmetlerin amac1; hasta veya bakıma muhtaç bireylerin; sağlık durumu ve hayat kalitesini iyileştirmek, hastanede kalış süresini kısaltarak hastane enfeksiyonu riskini en aza indirmek, hasta bireyin aile ortamına kısa sürede dönmesini sağlayarak moral desteği sunmak, hastane yatak kapasitesini verimli kullanıp hizmet maliyetini azaltmak, çocuk ve infantların ev ortamında gelişimini desteklemek, hastanın özerkliğini korumak, karar verme ve problem çözme konularında gelişmelerini desteklemektir (7, 8, 9). Evde bakım hizmetleri için en yaygın görüş "hastaların bağımsızlı̆̆ının sağlanması, hayat kalitesinin iyileştirilmesi ve sürekliliğin sağlanması için iyi bir çözüm yolu olmasıdır” (10).

1.3. Hizmet sunumunu yapan sağlık profesyonelleri: $\mathrm{Bu}$ alanda farklı disiplinlerle çalışma gerekmektedir. Hizmet ekibindeki kişiler birey ve ailenin ihtiyaç durumuna göre değişmekle birlikte; doktor, hemşire, sağlık memuru, sosyal hizmet çalışanı, psikolog, fizyoterapist, bakım destek/ refakat personeli, hasta takip personeli ulaşım sorumlusu gibi çalışanlardan oluşabilmektedir $(2,7)$.

1.4. Evde sunulan sağlık hizmetleri: Hekimlik ve hemşirelik hizmetleri, hastayı gözlem ve değerlendirme hizmetleri, sağlığı geliştirme ve koruma, palyatif bakım hizmetleri, fizik tedavi, tıbbi araç gereç hizmetleri, eczane hizmetleri ile psikiyatrik hizmetler olarak sayılabilir $(1,11$, 12).
1.5. Evde sunulan sosyal destek hizmetleri: Kişilerin ulaşımı, yaşam alanlarının bakımı, kişilerin özel bakımını kapsayan, içinde evlere yemek servis etme gibi hizmetler de olan sosyal hizmetlerdir. Sosyal hizmet çalışanları, bakım desteği çalışanları, aile bireyleri, din görevlileri gibi destek elemanları bu hizmetlerde görev alırlar $(7,13,14)$.

\subsection{Evde Bakım Hizmetlerinden Faydalanabilecek} Gruplar: Dünya Sağlık Örgütü (DSÖ)'nün evde uzun süreli bakım için hazırlanan teknik raporuna göre evde bakım hizmetleri, günlük yaşam aktivitelerinde yardıma ihtiyaç duyan her yaştan insanın uygun yaşam kalitesini sağlamak için aldığı her türlü bakımı kapsar. Hedef grupları; bulaşıcı ya da kronik hastalığı olan bireyler, etiyolojiden bağımsız olarak engelli bireyler, HIV/AIDS'li bireyler, kaza sonucu engelli olanlar, alg1 sorunu yaşayan bireyler, akıl hastalıkları olan bireyler, madde bağımlıları, doğal afetler ve diğer felaket kurbanı olan bireylerdir (11).

\subsection{Evde Bakım Hizmetlerinin Avantaj ve Dezavantajları}

1.6.1. Avantajlar: Bireyler özerkliklerini koruyabildikleri ve kendilerine ait ortamlarda daha mutlu olurlar. Ev ortamlarındaki tehlikelerin fark edilmesi ve çözüm bulunması daha kolaydır. Kendini gerçekleştirme yetileri, özgürlükleri ve diğer bireylerle iletişim halinde olmaları nedeni ile iyileşme süreçleri de daha hızlı olabilmektedir. Koruyucu sağlı hizmetlerine erişimin kolaylaşması, böylelikle hastane başvurularının azalması, hastane yatış gün sayısının da düşmesi ile enfeksiyon gelişme riski de azalması ile hastalara kendi yaşam alanlarında sunulan hizmetler hem aile için hem de ülke ekonomisi için ekonomik olacaktır. Evde bakım veren aile bireyleri de sürece dâhil olduğundan onların fiziksel ve ruhsal durumlarındaki değişiklikler daha erken fark edilebilir. Sağlık hizmetine ulaşamayan bireyler için önemli bir alternatiftir $(12,13,15)$.

1.6.2. Dezavantajlar: Sağlık çalışanı sürekli hastanın yanında olmadığından karşılaşılabilecek acil durumlara müdahalelerde sorun yaşanabilir (teknolojik cihaz sorunları, damar yolu ile ilgili tıkanıklık, sepsis, tromboz vb. sorunlar). Hizmeti veren personelin kendi çalışma ortamı dışında hizmet vermesi verimliliği azaltabilir, hizmet sunumunu da zorlaşabilir. Sağlık personeli, hasta ve aile ile iletişimde, güvenliğinin sağlanmasında sorun yaşayabilir. Hasta kendi yaşam alanını, mahrem alanını paylaşmak istemeyebilir. $\mathrm{Bu}$ durumda hasta bazı bilgilerini sağlık çalışanından gizleme yoluna gidebilir. Hasta bakımı sonrası oluşabilecek tıbbi 
atıkların bertarafında sorunlar yaşanabilir $(1,8,10,15,16$, 17).

\section{Türkiye'de Evde Bakım Hizmetleri}

Türklerde ilk olarak "Kam" veya "Baksı"lar tedavi işiyle ilgilenmiş, dini ritüelleri de yönetmişlerdir. Daha sonra "Otacı", "Emçi" veya "Atasagun" adı verilen hekimler bu işlerle ilgilenmişlerdir. Göçebe hayat sürdüklerinden sağlık hizmeti sunumlarının hasta kişinin evinde sunulduğu düşünülmektedir. Ebeler, gebelik döneminde ve doğumdan sonra ev ziyaretlerine gitmiş ve sağlık hizmetlerini evde sunmuşlardır (15). Günümüzde bu hizmetler, çoğunlukla yerel yönetimler, özel hastaneler, özel evde bakım merkezleri ve kamu hastanelerinin sundukları hizmetler olarak karşımıza çıkmaktadır (12). Evde Bakım Hizmetlerinin Sunumu Yönetmeliği'ne göre bu hizmetler; hekim önerisi ile hastalara, yaşadıkları ortamda, sağlık çalışanları tarafından rehabilitasyon, fizik tedavi, psikolojik destek tedavisi gibi ihtiyaçları karşılayacak şekilde sağlık hizmetlerinin sunulması olarak tanımlanmıştır (18). Bakanlık ve bakanlığa bağlı kuruluşların bünyesindeki eğitim-araştırma hastaneleri, genel veya dal hastaneleri, ağı-diş sağlığı merkezleri (ADSM) ve toplum sağlığ merkezleri (TSM) bünyesinde kurulan birimler ve aile hekimliği birimi (AHB) aracıllı̆̆ ile bu hizmetlerin sunumu sağlanır (19). Ekipte bir doktor, bir hemşire, bir sağlık memuru ve bir şoför görevlidir. İhtiyaç halinde bu ekibe psikolog, fizyoterapist, diyetisyen, sosyal hizmet uzmanı, bakım destek personeli gibi hekim dışı sağlık personeli eklenebilir (18).

Hizmetten yararlanmak için 4443833 numaralı telefon aranarak iletişim merkezlerine ulaşılabilir, ya da evde sağlık hizmeti sunumu yapan birimlere telefonla, sözlü veya dilekçeyle başvuru yapılabilir. Birimler, randevu sistemi kullanılarak ve mesai saatleri içinde hizmet sunumu gerçekleştirmektedirler (15).

Ülkemizde Sağlik Uygulama Tebliği'ne göre bu hizmetler, Sosyal Güvenlik Kurumu'nca ödenmektedir (10). Özel birimler de bu tür hizmetleri sunmaktadır. Hizmetlerin finansmanı resmi sigorta sistemi tarafindan değil cepten ödemelerle karşılandığından toplumun geniş kesimi özel evde bakım hizmetlerinden yararlanamamaktadır (15).

Türkiye'de Sosyal Hizmetler ve Çocuk Esirgeme Kurumu (SHÇEK) da bu hizmetleri vermektedir (10). Evde bakım aylığı bağlanabilmesi için Kanuna göre, özürlünün ikametinin olduğu evde kişi başı gelir düzeyinin aylık net asgarî ücretin 2/3'ünden daha az olması gerekmektedir. Aylık özürlü bireye bakmakla sorumlu kişiye verilmektedir (20).

Bakım Hizmetleri Stratejisi ve Eylem Planı'nda ülkemizdeki sosyal hizmetler sisteminde bazı aksaklıklar ve yetersizlikler olduğuna değinilmiş, iyi hizmet sunumunda sorunlar olduğundan ayrıca nüfusumuzun yaşlanmakta olduğu ve buna bağlı olarak da özürlülük sorununun gelecekte artacağ 1 belirtilmiş, temel sorunlar şu şekilde sıralanmıştır: Evde bakım hizmetlerinin yetersizliği, kurumsal bakımdaki hizmet sunumunda yetersizlikler, bakım hizmetleri konusundaki eğitimde yaşanan eksiklikler, hizmet sunumunda kullanılan destek teknolojilerindeki yetersizlikler, nüfusun tamamını içine alan bakım güvence sisteminin olmaması (20). Bakım hizmetleri konusunda sistematik bir yapılanmanın oluşturulması, ihtiyaçların karşılanmasını sağlayacak stratejilerin geliştirilmesi gereklidir.

\section{3. Örnek Ülkelerle Evde Bakım Hizmetleri}

$\mathrm{Bu}$ bölümde gelişmiş evde bakım hizmet modelleri olan Avrupa ülkelerindeki uygulamalardan bahsedilecektir. Avrupa'da meydana gelen demografik, epidemiyolojik, sosyal ve kültürel değişimler, geleneksel bakım yöntemlerinde de değişikliğe gitmeyi gerektirmiştir. Evde bakım hizmetleri sayesinde, akut ve uzun süreli hastaneye yatışların önüne geçilerek bireyi evinde ve toplum içinde tutmayı amaçlayan sürdürülebilir bir yaklaşım sunulmaktadır. (21). Bu ülkelerden İsveç, 2019'da 10.04 milyonluk toplam nüfusu ile dünyanın en gelişmiş toplumlarından biridir (22). İsveç vatandaşları sosyal ve ekonomik refah bakımından dünyada ilk sırada yer alır (23). İsveç'in köklü, evrensel, kamuya ait uzun vadeli bir bakım sistemi vardır. Uzun süreli bakımın mali sorumluluğu ulusal, bölgesel ve yerel yönetimler arasında paylaşılmaktadır. Ancak maliyetlerin yaklaşık \%85'i (2010) yerel ve bölgesel vergilerle karşılanmaktadır. İsveç’teki kurumsal sektörün küçülmesi, hizmet sunucularına yönelik teşviklerin yeniden düzenlenmesi ile kolaylaştırılmıştır (24). Gayri resmi bakım ağlarını ve aile bakımını desteklemek için önlemlere daha fazla yatırım yapılması yönünde çaba harcanmıştır (25).

Sağlık İsveç 273 ve Sağlık Hizmetleri Yasası (1982)'nın amacı, yaşa bakılmaksızın, sağlık hizmetlerine eşit erişime sahip herkes için iyi bir sağlık ve sağlık hizmetidir (26). Sağlık hizmetlerine en fazla ihtiyacı olan evde bakım alıcısına öncelik verilmesinden İl Meclisi sorumlu 
olmaktadır. Sosyal Hizmetler Kanunu'na göre belediyeler hizmet vermek, özel ihtiyaçları olan kişilere bakmak, ev ve kişisel bakım yapmak ve özel konutların inşa edilmesini, yenilenmesini sağlamak için belediyeleri teşvik etmek üzere kullanılır (27). Belediyeler, engelli bireylerin topluma katılabilmelerini, kendi yaşamlarını etkileyebilmelerini ve yaşlandıkça kendilerini güvende ve bağımsız hissetmelerini sağlamalıdır (28).

Evde bakım hizmeti esas olarak belediye veya özel kurumlar için çalışan maaşlı personel tarafından verilmektedir. Bir belediyenin sunduğu evde bakım hizmeti, birinci basamak sağlık hizmeti sunanlar tarafından ve evde yardım hizmeti evde yardım asistanı veya ev yardımcısı hemşiresi tarafından yapılan bir evde bakım ekibi tarafından sağlanır. Gönüllü ajanslar sayıca artmaktadır, ancak hala azınlıktadır. (29).

Almanya'da evde bakım hizmetlerinin maliyeti devlet, belediyeler, sivil toplum kuruluşları (STK) ve sağlık sigortası şirketleri arasındaki sözleşmelerle karşılanmaktadır. Sigorta acenteleri için erken tedavi önceliklidir. Bakım uzmanları bireyleri ziyaret eder ve karşılaştıkları risk faktörleri ve risklerin nasıl azaltılacağı konusunda onları bilgilendirir (30).

Almanya sosyal güvenlik alanında öncü ülkelerden birisidir. Almanya'da yaşayanların \%85'i standart sağlık güvencesine sahipken geriye kalan kısım ise daha yüksek güvencelerden yararlanmaktadır (31). Bakıma muhtaç kişilere bakım hizmetlerinin evde sunulması düzenlenmiştir ve bakıma muhtaç engelli ve yaşlı bireye ve ona bakan ailesi hizmetlerden faydalanır (32).

Bireyler ayni veya nakdi bakım yardımı almaktadır. Aileden biri bakıma muhtaç durumda olan kişiye bu hizmetleri sunabilmesi için doğrudan nakit yardım talep edebilir (33). Hizmet kapsamında; beden temizliği, yemek yeme, mobilite, evle ilgili işler, tadilat işleri, tıbbi yardım, sosyal bakım gibi hizmetler vardır $(34,35)$. Bakım hizmetini yerine getiren kişinin dinlenme ihtiyacı da giderilir ve yedek bakım adı verilen geçici bir bakım hizmetinden yararlandirılır (33).

Evde bakımı teşvik etmek için bakımı yapan kişilere belirli şartlar altında emeklilik ve işsizlik sigortası primlerinin ödenmesi gibi sosyal güvence uygulamaları başlatılmıştır. Bakıma muhtaç kişiler veya yakınları için "destek noktaları" kurulmuştur. Her yıl yardımların miktarını artırma hedefleri vardır (36).
Almanya'nın evde bakım konusunda kaygıları da vardır. Rehabilitasyon bakımının yanı sıra önleme, sağ lığı geliştirme ve bakım hedeflerine henüz ulaşılamamıştır. Gelecek için önemli miktarda personel sıkıntısı beklenmektedir bunun için de gerekli önlemler alınmalıdır (37).

Hollanda'da sosyal bakım hizmetleri, Sağlık Bakanlığı tarafından seçilen ve denetlenen sağlık şirketleri, STK'lar ve serbest bakım verenler tarafından sağlanmaktadır. Palyatif bakım ücretsizdir. İyileştirici tedavi maliyeti çoğunlukla hastalık fonları ve özel sigorta poliçeleri tarafından ödenir (37). Bakıma muhtaç bireyler yasal olarak korunmaktadır. Bakım hizmetleri, aile fertleri, profesyonel bakıcılar, sivil toplum kuruluşları ve bakım şirketlerinden alınabilir. Kişinin bakıma muhtaçlık durumu, derecesi ve ihtiyaca göre bu hizmetler biçimlenip zengin ve değişken hale gelmiştir. Ev hemşireliği, temel bakım, temizlik işleri, sağlık hizmetleri, rehabilitasyon hizmetleri, gece ve gündüz bakımı hizmetleri sunulmakta ve yaşlılar, engelliler, kronik hastalığı olanlar, iyileşme dönemindeki hastalar ve lohusalar faydalanmaktadır. (7).

Verilen hizmetler; evde kişisel bakım, evde sağlık bakımı, evde sosyal bakım ve evde yardıma ilişkin hizmet ve düzenlemeleri içerir (38). Hollanda, evde bakım alanında, köklü geçmişe sahip bir sosyal refah ülkesidir. Ev ziyaretleri ile başlayan bu hizmetler günümüzde eğitim kurumlarının açılmasıyla birlikte profesyonel hizmet sunucuları ile verilmeye başlanmıştır. Bireyler tercihlerine göre, ayni ya da nakdi yardım alabilir, "Bakım ve Değerlendirme Merkezi”nin inceleme ve değerlendirmeleri ile yardım süresi belirlenir (38).

\section{SONUÇ VE ÖNERÍLER}

Avrupa ülkelerine baktığımızda yaşlı nüfusun, bakıma muhtaç kişilerin sayısının hızla arttığ 1 , henüz çözüm yolu arayışında olmayan ülkelerin de bakım hizmetleri kapsamında sistemlerini iyileştirmek zorunda oldukları açıktır. Bakım hizmetlerin sistemli olarak uygulanmakta olduğu birçok Avrupa Birliği ülkesi, bakıma muhtaç kişileri alıştıkları sosyal çevreden ayırmadan hizmet sunmak için bu hizmetleri evde sunmaya yönelmişlerdir. Ayrıca kronik hastalıkların yüksek prevalansı ve hastane bakım maliyetinin artması, uzun süreli bakım hizmetleri sunmak için evde bakımın düşük maliyetli bir alternatif olarak yeniden düşünülmesi gerektiği ülkelerin önem verdiği bir durum haline gelmiş̧ir. İsveç'te bu hizmetler yerel ve bölgesel vergilerle, güçlü teşvik ve yatırımlarla 
sağlanmakta, hizmetler belediye veya özel şirketler aracıllı̆g 1 ile sunulmaktadır. Almanya' da evde bakım hizmetleri devlet, belediyeler, STK'lar ve sağlik sigorta şirketleri arasındaki sözleşmelerle karşılanmakta, evde bakım, tesislerdeki kurumsal bakımdan öncelikli olarak değerlendirilmektedir. Hollanda'da ise çoğunlukla hasta, özürlü ve yaşlı bireyler arasında ayırım yapılmadan, bakıma muhtaç bireyleri yasal anlamda korumakta, Sağlık Bakanlığı tarafından seçilen ve denetlenen sağlık şirketleri, STK ve serbest bakım verenler hizmet sunmaktadır.

Ülkemiz için de, özellikle yaşlı, özürlü, bakıma muhtaç bireylerin artması nedeni ile ihtiyaç duyulan hizmetlerdir. Hizmetin nasıl, kim tarafindan, hizmetin ne kadarının evde sunulacağı gibi konuların netleştirilmesine ihtiyaç vardır. Uzman çalışanlarla, adil iş yükü sağlayarak çalışan motivasyonunu ve verimliliğini de hedefleyerek standartlaşmış hizmet sunumu sağlanmalıdır. Hastalara tıbbi desteğin yanında sosyal desteğin de sağlanmasını hedefleyen evde bakım hizmetlerinin daha efektif olabilmesi için ihtiyaç sahiplerinin yaşam kalitesini yükseltmeye yönelik iyileştirmeler de yapılmalıdır. Bunun için bakanlıklar, belediyeler, sivil toplum kuruluşları, dernekler arasında koordinasyon sağlanmalıdır. Ülkemizde bu hizmetlerin sunumunda verimin arttırılmasına katkı sağlamak, kaliteli evde bakım hizmeti sunabilmek için ülke örnekleri detaylı incelenmeli, Türkiye için eleştirel bakış kazanıp ülke deneyimlerinden faydalanılmalı, hem önleyici hem de terapötik hizmetler bütünsel bir yaklaşımla sunulmalıdır.

\section{KAYNAKLAR}

1. Altuntaş M, Y1lmazer TT, Güçlü YA, Öngel K. Evde sağlık hizmeti ve günümüzdeki uygulama şekilleri. Tepecik Eğit Hastanesi Dergisi. 2010; 20 (3): 153-8.

2. Karahan A, Güven S. Yaşlılıkta evde bakım. Tur J Geriatrics. 2002; 5(4): $155-9$.

3. Başbakanlık Mevzuatı Geliştirme ve Yayın Genel Müdürlüğü. Evde bakım hizmetleri sunumu hakkında yönetmelik. Ankara 10.03.2005; Resmi Gazete: Say1 25751.

4. Feldman FH, Waliser MN, Gould DA, Levine C. When the caregivers needs care: the plight of vulnerable caregivers. Am J Public Health. 2002; 92(3): 409.

5. Taşdelen $\mathrm{P}$, Ateş M. Evde bakım gerektiren hastaların bakım gereksinimleri ile bakım verenlerin yükünün değerlendirilmesi. Hemşirelikte Eğitim ve Araştırma Dergisi. 2012; 9: 22-29

6. Oğlak S. Uzun süreli evde bakım hizmetleri ve bakım sigortas1. Turkish Journal of Geriatrics. 2007;10 (2): 100108.
7. Aydın D. Sağlıklı Nesiller Derneği, Evde bakım hizmetleri. Sağlık ve Eğitim Yayınları $1 \mathrm{http} / /$ www.dursunaydin. com/media/01daff-bbqxp.pdf.2005. Ankara. [Erişim tarihi:17.05.2020].

8. Çoban M, Esatoğlu A E. Evde bakım hizmetlerine genel bir bakış. T Klin Tıp Etiği-Hukuku-Tarihi. 2004;12.109-120.

9. Can Ö, Ünal N. Evde bakım ve tedavi. Türk Yoğun Bakım Derneği Dergisi. 2008; 6(4): 6-13.

10. Özer Ö, Şantaş F. Kamunun sunduğu evde bakım hizmetleri ve finansmanı. Acıbadem Üniversitesi Sağlık Bilimleri Dergisi. 2012; 3 (2):96-103.

11. World Health Organization Technical Report Series 898. Home-Based Long Term Care. Geneva, 2000.

12. Pınar R. Türkiye'de evde bakımda mevcut durum. Akademik Geriatri. 2010; 153-156.

13. Yılmaz M, Sametoğlu F, Akmeşe G, Tak A, Yağbasan B, Gökçay S. Sağllk hizmetinin alternatif bir sunum şekli olarak evde hasta bakımı. İstanbul Tip Dergisi 2010; 11(3): 125132.

14. Ekinci G, Sur H. Türkiye'de evde bakım hizmetleri organizasyonu için bir model önerisi. Sağlıkta Düşünce ve Tip Kültürü Dergisi. 2012; 24.

15. Aksoy H, Kahveci R, Şencan İ, Kasım İ, Özkara A. Evde bakım hizmetlerine genel bakış ve Türkiye'deki mevcut durum. 2015; 7(2): 162-168.

16. Marks IM. Home-based versus hospital based care for people with serious mental illness. British Journal of Psychiatry. 1994; 165:179-194.

17. Karadağ M. Türk Silahlı Kuvvetleri'nde görevli hekim öğretim üyelerinin evde bakım hizmetleri konusundaki görüşleri. Yüksek Lisans Tezi. Ankara, 2006.

18. Evde Bakım Hizmetleri'nin Sunumu Yönetmeliği. Güncelleme Tarihi: 20.10.2016. https://www.saglik.gov. $\operatorname{tr} / \mathrm{TR}, 10474 /$ evde-bakim-hizmetleri-sunumu-hakkinda yonetmelik.html. [Erişim tarihi: 11.06.2020].

19. Resmî Gazete. Sağlık Bakanlı̆̆ı ve Bağlı Kuruluşları Tarafindan Evde Sağlık Hizmetlerinin Sunulmasına Dair Yönetmelik. 27 Şubat 2015. Sayı: 29280.

20. Bakım Hizmetleri Stratejisi ve Eylem Planı (2011-2013) https://www.resmigazete.gov.tr/eskiler/2011/01/20110119-6. htm [Erişim Tarihi:12.06.2020].

21. Somut gerçek, Avrupa'da evde bakım hizmetleri. World Health Organization. 2008.

22. https://www.statista.com/study/48401/sweden/ [Erișim Tarihi:15.03.2021].

23. Global AgeWatch Index 2013 Insight Report. [Erişim Tarihi: 18.03.2021]

24. Ilinca S, Leichsenring K, Rodrigues R. From care in homes to care at home: European experiences with (de) institutionalisation in long-term care. Policy Brief. December 2015.

25. Fukushima N, Adami J, Palme M. The long-term care system for the elderly in Sweden. Eneprı Research Report. No. 89. 2010.

26. The Health And Medical Services Act In Swedish: Hälso och Sjukvårdslagen SFS. Stockholm.1982:763. 
27. Le Bihan B, Martin CA comparative case study of care systems for frail elderly people: Germany, Spain, France, Italy, United Kingdom and Sweden. Social Policy and Administration. 2006; 40 (1):26-46.

28. Fagerström C, Willman A. Home care across europe case studies: Sweden. Edited by Nadine Genet, Wienke Boerma, Madelon Kroneman, Allen Hutchinson, Richard B Saltman. 2013: 272-279.

29. Garms V H: Home care across Europe case studies: Germany. Edited by Nadine Genet, Wienke Boerma, Madelon Kroneman, Allen Hutchinson, Richard B Saltman. 2013: 110-118.

30. Torun N, Tengilimoğlu D, Khan MM. Home health services in Turkey: A case study based on patient survey of home health services users in the province of Ankara. International Journal Of Health Management And Tourısm. 2016; 1(2): 77-97.

31. Özmete E, Hussein S. Türkiye'de yaşlı bakım hizmetleri raporu: Avrupa'dan en iyi uygulama örnekleri ve Türkiye için bir model tasarımı. Aile ve Sosyal Politikalar Bakanlığ Sosyal İçerme Politikaları Alanında Kurumsal Kapasitenin Artırılması Projesi. TC Aile ve Sosyal Politikalar Bakanlığı. Ankara. 2017.
32. Balcı GŞ. Sosyal güvenlik hakkı açısından yaşlı bakımı. İstanbul. 2017.

33. Hekimler A. Federal Almanya'da sosyal bakım sigortasının temel esasları. Çalışma ve Toplum. 2015; 44 (1): 45-76.

34. Metin M. Almanya Federal Cumhuriyeti'ndeki zorunlu bakım sigortası ve Türkiye'deki uygulanabilirliği. Uzmanlık tezi. Dış ilişkiler ve yurtdışı işçi hizmetleri genel müdürlüğü. Ankara. 2014.

35. Yakınların Bakımı. https://www.muenchen.info/soz/ pdf/LHM_Pflege_angehoeriger_tuerkisch.pdf [Erişim Tarihi:18.03.2021].

36. Şuözer N. Almanya'da Bakım Sigortasında Çok Şey Değişecek. 2016. https://www.arti49.com/almanyadabakim-sigortasinda-cok-sey-degisecek-630434h.htm [Erişim Tarihi:15.03.2021].

37. Erdil F. Yaşlanan toplum ve yaşlının evde bakımı. http://ekutuphane.teb.org.tr/pdf/tebakademi/geriatri_2009/23.pdf [Erişim Tarihi:13.12.2020].

38. Danış MZ, Solak Y. Evde bakım hizmetlerinin organizasyonu: Hollanda örneği. The Journal of Academic Social Science. 2014; $24: 57-71$. 